\title{
Breves Considerações sobre os Aspectos-chave do RMG/RSI e suas Contradições
}

Elisabete Lopes*

\begin{abstract}
$\mathrm{R}_{\mathrm{e}}$ esumo: Propõe-se uma reflexão em torno de algumas questões chave que enquadram o RMG/RSI a propósito da leitura da recente obra de Fernando Diogo, Pobreza, Trabalho e Identidade, que procura perceber o efeito do RMG/RSI na relação dos beneficiários com o mundo do trabalho, em especial na construção da sua identidade social. Por outro lado, interroga e contribui para compreender o sentido mais profundo da inserção social, das lógicas dos actores e suas racionalidades e para o peso simbólico das designações produzidas pelo Estado ao nível do seu efeito na construção das identidades sociais.
\end{abstract}

Palavras-chave: RMG; Políticas sociais; Identidade.

Em Portugal, a temática da inclusão e exclusão tem-se mantido no centro dos debates políticos e científicos, que se esforçam para conhecer e combater as suas múltiplas causas, apurar as suas consequências e manifestações e criar instrumentos válidos de combate a esta, ainda, "nova questão social". No âmbito desses instrumentos, tem vindo a assumir importância crescente a implementação de um leque de políticas conotadas "com a passagem de um Estado Providência passivo para um Estado Providência activo e com a emergência de um problema novo portador de particulares conotações éticas e políticas, o da obrigação de retribuir as ajudas recebidas do Estado com uma contribuição activa, consistindo esta quase sempre em trabalho" (Hespanha, 2002:4). É neste contexto que se inclui o Rendimento Mínimo Garantido (RMG) ou, do actual Rendimento Social de Inserção (RSI) criado na continuidade daquela medida de protecção social ${ }^{1}$.

Os debates sobre a pertinência da implementação de uma medida como o RMG/RSI marcam ainda actualidade, em grande parte por se tratar de um instrumento político que tenta garantir a subsistência a todos aqueles que não dispõem de recursos mínimos de sobrevivência, independentemente de terem contribuído para o sistema de segurança social.
Procuraremos nas páginas que se seguem destacar alguns aspectos que, em nosso entender, marcam ainda o debate (nem sempre pacífico) sobre este importante recurso para a minimização das formas de pobreza extrema em Portugal. E fazemo-lo a propósito da leitura da recente obra de Fernando Diogo, Pobreza, Trabalho e Identidade que procura perceber o efeito do RMG/RSI na relação dos beneficiários com o mundo do trabalho, em especial na construção da sua identidade social. Trata-se, em nossos entender, de uma obra a reter para os profissionais de diferentes disciplinas que, de uma maneira directa ou indirecta, estão ligados à execução de Políticas Sociais mas, também, àqueles com responsabilidades na definição e planeamento estratégico das mesmas. Extremamente rica em resultados, mas também na leitura compreensiva mais vasta dos fenómenos em análise, trata-se de uma obra que muito contribui para o conhecimento da sociedade açoriana ${ }^{2}$. Porém, a sua pertinência vai mais além, porquanto, interroga e contribui para compreender o sentido mais profundo da inserção, das lógicas dos actores e suas racionalidades e para o peso simbólico das designações produzidas pelo Estado ao nível do seu efeito na construção das identidades sociais.

\footnotetext{
"Socióloga. Investigadora do CET. Contacto:elis.morgado@gmail.com

${ }^{\prime}$ Fernando Diogo (2007) é um dos autores que defende que a passagem do RMG para RSI, não introduziu nada de novo ao nível do seu aspecto central: a relação entre a prestação pecuniária e o programa de inserção.

2 E mais concretamente a ilha de S.Miguel onde se verifica que 7\% da população desta ilha sobrevive com o RSI.
} 


\section{Questões e contradições: o quadro legal da criação da medida}

A principal ideia a reter da legislação é a ideia de que o RMG /RSI constitui uma prestação do regime não contributivo e um programa de inserção que assenta na realização de acções de inserção com vista à melhoria da inserção social dos indivíduos. $\mathrm{Na}$ sua mais recente obra, Fernando Diogo (2007) encontrou na legislação e nos discursos dos seus responsáveis aquilo a que designou por beneficiário ideal $^{3}$, isto é, o beneficiário imaginário para o qual se produziu a legislação. Trata-se de alguém que se encontra afastado da esfera do trabalho, que não tem capacidade de sair por si só da situação de pobreza, precisando de apoio para o fazer. Por outro lado, o beneficiário que subjaz à legislação é alguém que se encontra numa situação de desinserção social, já que se pressupõe que deve ser inserido socialmente. Por outro lado, "a categoria de beneficiário ideal impõe-se aos indivíduos, projectando-se como princípio identitário sobre estes, sendo utilizada pelos outros para os classificarem. O peso da designação estatal condiciona e orienta a forma como os beneficiários se relacionam com o Estado e com os outros em geral. Desta maneira, obriga-os a contar com ela na produção e reprodução das suas identidades sociais, implicando o desenvolvimento de estratégias identitárias para os indivíduos lidarem com essa forma de classificação nas suas transacções" (Diogo, 2004:22) .

\section{A noção de inserção}

Na legislação a noção de inserção, a par da prestação pecuniária, é uma componente fundamental da medida. Contudo, ela não possui uma definição clara daquele conceito, o que tem implicações na clarificação de outros conceitos a ele associados, tais como o acordo de inserção ou acção de inserção. É devido a esta falta de clareza que se devem os equívocos e contradições que contribuem para aumentar a tensão social associada à condição de beneficiário do RMG. Por outro lado, a falta de clareza na definição de inserção resulta do facto de a medida responder, simultaneamente, aos dois termos da discussão entre welfare e workfare e que, tendo em conta a natureza dos processos que encerram, são de difícil conciliação. Isto é, "procura-se responder, simultaneamente, à concepção do pobre como sujeito de um processo de exclusão para o qual existem apoios compensatórios e à concepção do pobre como alguém que é desincentivado do trabalho pelos apoios sociais, sendo necessário exigir contrapartidas neste domínio" (Diogo, 2007:206).

Os objectivos da medida centram-se no minorar os efeitos mais severos da exclusão social e proporcionar aos indivíduos condições para que, através do trabalho, se autonomizem e se insiram socialmente. Contudo, a própria legislação sobre a medida é pouco esclarecedora quanto à distinção entre os conceitos de autonomização e inserção. Assim, "se o acesso à medida depende dos rendimentos familiares serem baixos ou inexistentes, deixar de o ser depende da substituição do montante fornecido sob a forma de prestação por outro tipo de fontes, entre as quais avulta o rendimento pelo trabalho" (Diogo, 2007:125). Com efeito, é através das questões referentes ao rendimento (critérios monetários) que se define o acesso à medida, assim como se afere as condições de saída da medida. Deste modo, uma das características do beneficiário ideal que subjaz à legislação diz respeito a "alguém que não é autónomo (no sentido em que tem de depender de terceiros) do ponto de vista económico e em relação ao emprego e formação profissional (estando estes dois aspectos estritamente ligados), mas também do ponto de vista social" (Diogo, 2007:127).

O que parece faltar na legislação, adverte o autor, é uma reflexão em torno da ideia de inserção, já que se corre o risco de transformar as desigualdades sociais em desigualdades individuais: "Esta concepção passa pela ideia de que os beneficiários são socialmente desinseridos produzindo um efeito

\footnotetext{
${ }^{3}$ O conceito de beneficiário ideal é construído com base nas propostas de Ogien (1983) e Paugam (1991) referentes à noção de assistido de Simmel e no conceito de categoria oficial de Demazière e Dubar (1997)

${ }^{4}$ Para responder à situação de tensão identitária o autor identifica três tipos de estratégias: as de distanciamento, de orgulho e de defesa que os indivíduos mobilizam consoante percepcionem ser mais vantajoso para si nos quadros de interacção quotidiana. "o que as distingue não são as condições de existência dos beneficiários (...), mas a forma como se mobilizam para se construírem a si próprios" (Diogo, 2007:203). A redução daquela tensão visa maximizar a imagem de si para si e actuar sobre a identidade para os outros podendo assumir quatro configurações: identidade para os outros positiva e identidade para si positiva; identidade para os outros positiva e identidade para si negativa; identidade para os outros negativa e identidade para si positiva; identidade para os outros negativa e identidade para si negativa. De acordo com o autor, os pobres são a categoria social que mais lança mão da terceira configuração identificada para a resolução da tensão identitária enquanto a quarta configuração é mais provável ser encontrada nos "sem-abrigo" e em outras categorias de indivíduos em situação de pobreza material.
} 
paradoxal: ao procurar-se promover a inserção dos indivíduos na vida social está-se, no plano simbólico, a estigmatizá-los e a classificá-los" (Diogo, 2007:206). Torna-se ainda necessário questionar se os efeitos do programa de inserção conseguem contrabalançar os efeitos da estigmatização e se há alternativa à existência de apoios sociais, nos termos genéricos em que o RMG/RSI se desenvolve.

Uma outra contradição encontrada pelo autor na análise da legislação que cria o RMG é a aquela entre o enfoque da legislação no trabalho e no rendimento pelo trabalho e o discurso dos responsáveis que evocam a dimensão social da inserção. Por outro lado, a ausência dos agentes económicos e suas organizações representativas nas comissões locais de acompanhamento, é também sintomática do desinteresse das entidades com responsabilidade nas esferas do trabalho, do emprego e da economia na medida Esta ausência contrasta com as intenções de melhorar o desempenho dos beneficiários nestas áreas ${ }^{5}$.

Outro aspecto que configura este apoio social é o facto de ser temporário e é-o devido à existência de um programa cujo objectivo é criar condições de autonomização ou de saída da medida. O carácter temporário que se confere ao RMG/RSI leva à criação de expectativas de uma saída rápida dos beneficiários do sistema, o que é contraditório com as condições criadas pela medida para o fim do apoio e com as próprias condições de produção da situação de pobreza no nosso país, cuja tendência é para a sua reprodução ao longo do tempo (Diogo, 2007:34).

\section{A noção de trabalho}

É através da ideia de inserção que se estabelece na legislação a relação entre RMG e trabalho, uma vez que a questão da disponibilidade para o trabalho e para a inserção pelo trabalho surge com significativo destaque nos programas de inserção e, por conseguinte, como condição essencial para o recebimento da prestação pecuniária (Diogo, 2007:131). Isto é, um dos principais elementos que estrutura a ideia de beneficiário ideal subjacente à legislação é, precisamente, a relação com o mercado de trabalho.
A noção de trabalho surge na legislação apenas como fonte de rendimento cujo aumento permite idealmente a autonomização dos sujeitos em relação à medida. Esta é uma contradição importante uma vez que os benefícios e privilégios consubstanciados na ideia de emprego desenvolvem um papel importante no posicionamento social e na identidade social dos indivíduos. De facto, o que está em jogo na relação dos indivíduos com a esfera do trabalho não é apenas este como actividade ou fonte de rendimento mas, sobretudo, a definição do lugar de cada um na sociedade onde assumem importância aspectos que se traduzem na ideia de emprego (benefícios sociais inerentes) e aspectos da vivência subjectiva como por exemplo a satisfação com o trabalho que contribuem para a produção e reprodução da identidade social e para o lugar do trabalho nela (Diogo, 2007:138).

Tal como enfatiza Fernando Diogo "o problema está na desadequação desta ideia de relacionamento com o mercado de trabalho com aquilo que é a realidade desse relacionamento por parte dos beneficiários. A ideia de trabalho presente na legislação e documentação complementar é qualquer trabalho, no entanto, o trabalho inclusivo (o que autonomiza em relação à medida) não é qualquer trabalho, é o trabalho que se caracteriza pelos direitos sociais associados ao trabalho assalariado (protecção na doença, na velhice e no desemprego), distinto da situação de extrema precariedade em relação ao emprego característica da maioria dos beneficiários" (Diogo, 2004b). A autonomização da medida só é efectiva se se ancorar em mecanismos de inserção sustentáveis, parte dos quais podem ser conseguidos através de empregos estáveis, legais e idealmente proporcionando um vínculo efectivo. De facto, "são estes que permitem a realização de cálculos e projeç̧ões em relação ao futuro a partir de uma base de confiança em si sem preocupações sobre a sobrevivência física, que limitam gravemente a capacidade de os indivíduos realizarem este exercício"(Diogo, 2007:207).

Em suma, a qualidade de inserção pelo trabalho é um aspecto ausente na legislação, não levando em linha de conta os efeitos da precariedade e da clandestinidade no processo de construção identitária, mas também na reflexão sobre as condições

\footnotetext{
${ }^{5} \mathrm{Na}$ sua pesquisa, o autor corrobora, através da análise estatística de uma base de dados do Instituto de Acção Social, as conclusões de outros estudos que apontam para o facto de as acções de inserção não se dirigirem prioritariamente para a formação profissional e o emprego (Diogo, 2007:137).
} 
económicas que tornam os indivíduos elegíveis para a medida. Por outro lado, as condições de inserção dos beneficiários contribuem, segundo o autor, para a minorização do trabalho enquanto espaço de reconhecimento identitário. A precariedade, para além de ter efeitos na probabilidade do empobrecimento, é equacionada com um factor importante na diversificação dos princípios identitários, alternativos, concorrenciais ou complementares ao trabalho, a partir dos quais os indivíduos se definem. (Diogo, 2007:76) ${ }^{6}$. Para Fernando Diogo, a precariedade, enquanto forma de relacionamento do indivíduo com o emprego, destaca-se pelo seu potencial de ampliação da tensão identitária, particularmente nesta população que apresenta escassez de algum tipo de recursos e com uma precariedade de emprego do tipo "carrossel sucessivo", como é referido pelo autor, entre empregos precários e desemprego de longa duração. É justamente a ausência da perspectiva do trabalho enquanto emprego na legislação e no discurso dos responsáveis que mina, à partida, o sucesso da medida dada a centralidade do trabalho como valor e como principal elemento do posicionamento do indivíduo na sociedade continua a ser inquestionável. (Diogo, 2007:139).

\section{A invisibilidade dos programas de in- serção para os beneficiários}

A par da prestação pecuniária, o programa de inserção delineado com os beneficiários é, como se sabe, a pedra de toque da Medida, sendo este, aliás, que lhe confere um carácter inovador. É através do acordo de inserção (e de um conjunto de acções que se esperam integradas) que se procura construir percursos e trajectórias de vida que conduzam à autonomia dos indivíduos, isto é, à saída (de forma sustentada) da condição de pobreza e exclusão.

De acordo com Fernando Diogo, a existência de um programa de inserção deve-se a três ordens de razão: defesa face às críticas neoliberais que alegam o desincentivo ao trabalho que os apoios estatais alegadamente provocam; a ambição de combater a exclusão social promovendo activamente a inserção social; e o combate ao desemprego (Diogo, 2007:130). Com a existência do programa de inserção procura-se, segundo o autor: 1) relativizar e limitar o direito consagrado pela natureza da prestação do regime não contributivo da segurança social, tornando-o num direito condicionado, que limita a universalidade com que alguns o caracterizam; 2) o combate à exclusão social através da promoção da inserção social no pressuposto de que o combate não deve ser entendido apenas como uma ajuda ao rendimento, mas como uma forma de promover a integração social proporcionando a capacidade de autonomia dos indivíduos perante os apoios estatais e 3) o combate ao desemprego.

Em 2002, nos estudos de avaliação do RMG desenvolvidos pelo Instituto para o Desenvolvimento Social (IDS), verificou-se que $70 \%$ dos beneficiários consideravam que a expressão inserção nunca lhes havia sido explicada (Castro et al., 2002). No mesmo sentido vão as conclusões da maior parte dos estudos de aprofundamento dos diferentes perfis dos beneficiários levados por aquele Instituto onde, através de entrevistas aprofundadas a diferentes perfis de beneficiários, se verifica este mesmo desconhecimento. Num desses estudos, onde tivemos oportunidade de participar ${ }^{7}$, todas as famílias entrevistadas tiveram um Plano de Inserção e, em quase todos, mesmo não sendo estruturante, esse plano tinha dimensões muito positivas e algumas de médio prazo. Mas, dada a forma difusa com que este foi apreendido, mais do que falar em projectos de inserção o que parece ter ocorrido foram "intenções" de inserção, nalguns casos incapazes de se traduzir num projecto efectivo de inclusão. $\mathrm{O}$ que estes estudos de natureza qualitativa acabaram por "denunciar" é uma enorme contradição entre o modo como a legislação define a medida, o que é exigido dos beneficiários como contrapartida, e o modo como estes se apropriam do apoio e da noção que têm dele.

A polarização no apoio financeiro imediato tem como efeito a desvalorização de dimensões que, a médio prazo, serão com certeza bem mais estruturantes na sua mudança e da sua família: a formação

\footnotetext{
${ }^{6}$ Quanto aos efeitos possíveis da precariedade prolongada na relação com o trabalho e na identidade perante o trabalho, conclui o autor que a "precariedade e características associadas aos empregos disponíveis para os indivíduos mais pobres pode ter como consequência uma maior dificuldade destes construírem uma identidade social em que a identificação ao trabalho desempenhe um papel importante, podendo levar a que estes secundarizem e mesmo que o rejeitem, desenvolvendo prioritariamente os seus investimentos identitários noutros princípios que não o trabalho ou tendo como consequência sua rejeição como prática" (Diogo, 2007:49).

7 GUERRA, Isabel (co ord), LOPES, Elisabete, AMOR, Teresa, 2002, Avaliação de impactes do Rendimento Mínimo Garantido, caracterização dos perfis dos beneficiári9os RMG, Minorias Étnicas, Lisboa, Instituto para o Desenvolvimento Social.
} 
profissional, a escolarização dos filhos, etc. Esta visão de curto prazo faz com que uma medida de grande elaboração sociopolítica, e pouco usual, seja dificilmente apreendida. $\mathrm{O}$ acordo de inserção emerge, assim, com pouco sentido per si, quer na cultura de assistência de alguns, quer na estrutura imediata do modo de vida dos beneficiários.

O estudo de Fernando Diogo (2007) que temos vindo a citar aponta mais uma vez para o desconhecimento da ideia de inserção por parte dos beneficiários. $\mathrm{O}$ desconhecimento generalizado da ideia de inserção entre os beneficiários (apesar de a maioria ter assinado um acordo de inserção) é equacionada a partir do desencontro entre o modo como a lei (através do conceito de beneficiário ideal) define o beneficiário, as suas necessidades e os seus problemas e o modo como os próprios beneficiários se definem naquelas dimensões. Com efeito, os entrevistados pautam o seu discurso sobre a medida com as ideais de necessidade e ajuda, centrando-se exclusivamente na prestação e nos seus efeitos materiais no quotidiano (Diogo, 2007:193).

Este desconhecimento é significativo pois não se está na presença de uma simples negação da ideia de inserção. Com defeito, a distância entre a visão institucional do RMG e a dos beneficiários, expressa a partir do desconhecimento da própria expressão "programa de inserção" começa a construir-se através das contradições internas ao próprio processo institucional que temos vindo a dar conta.

\section{A construção da identidade social e as marcas identitárias do estatuto de beneficiário}

A questão da identidade social é cada vez mais central nas nossas sociedades porque ela é cada vez mais uma construção e menos um dado adquirido. $\mathrm{E}$ isto porque o lugar do indivíduo na sociedade já não é adquirido pelo processo de socialização e reconfirmado por trajectórias sociais mais ou menos estáveis e previsíveis, mas sim o resultado da interacção do indivíduo com as instâncias de socialização que do mundo de trabalho se espalha à vivência em sociedade (Diogo, 2007:3).
Ser pobre e beneficiário do RMG são rótulos ou princípios classificadores que instituições e indivíduos atribuem a outros indivíduos. Para Diogo (2007), os indivíduos em situação de pobreza e beneficiários de alocações sociais constituem uma categoria social onde a tensão identitária ${ }^{8}$ é forte devido às condições de escassez de recursos e da etiquetagem social a que são sujeitas, assentes nos estigmas sociais associados à pobreza, mas também às características do relacionamento com a esfera do trabalho e com os serviços de Acção Social.

Enquanto dimensão negativa, o RMG confere aos seus beneficiários o estigma da assistência, traduzido na incapacidade de gerirem autonomamente as suas vidas e na ideia socialmente desvalorizada de pobreza. Há, no entanto, uma dimensão positiva da medida que ressalva da legislação, uma vez que o programa de inserção permite o acesso a mecanismos de melhoria das competências face ao emprego, nomeadamente, através da formação profissional, ou mesmo o acesso ao emprego. Desta forma, o estatuto que o RMG confere pode ser um elemento potenciador da tensão identitária entre identidade para si e para os outros ou um elemento atenuador desta tensão, ao proporcionar competências e recursos que permitam uma melhor identificação dos indivíduos como empregados/trabalhadores para si e para os outros (Diogo, 2007:69).

De acordo com a análise empírica do Estudo que temos vindo a citar é possível extrair três grandes conclusões:

- O RMG não se constitui como um recurso para reduzir a tensão identitária, ao contrário aumenta-a. A ideia de inserção contemplada na legislação não leva em linha de conta o modo como os indivíduos se definem e se relacionam com a medida. Para os beneficiários o RMG é uma prestação pecuniária que ajuda a sobreviver desconhecendo-se as ideias associadas ao conceito e programa de inserção. Ou seja, está subjacente um sentido distinto do que é enunciado na legislação, que deriva da experiência de vida e do universo social a partir do qual se constroem os beneficiários

\footnotetext{
${ }^{8}$ A tensão identitária é o desequilíbrio provocado pela não coincidência entre a forma como o indivíduo se vê e se identifica e a forma como os outros o fazem (Diogo, 2007:33).
} 
(Diogo, 2007:147). Uma das explicações para a incapacidade da medida em funcionar como um recurso que permite reduzir a tensão identitária prende-se com o facto de a maioria das acções do plano de inserção não serem ligadas à formação profissional, ao trabalho e ao emprego e, se assim é, tratam-se de acções que não geram rendimentos que permitam a autonomização da medida. Tem, no entanto, um efeito ao nível da redução das tensões do quotidiano uma vez que é percepcionada pelos indivíduos (que trabalham) como um complemento dos seus rendimentos, que permite viver uma vida mais desafogada e um importante apoio para fazer face às necessidades básicas e em particular à alimentação.

Outro aspecto que concorre para o aumento da tensão identitária é, por um lado, o estigma social associado à condição de beneficiário do RMG e, por outro, a reprovação social associada ao afastamento dos indivíduos do mercado de trabalho possível pela existência de várias fontes de rendimento (apoios e prestações familiares de vária ordem).

\section{- A medida impõe-se aos indivíduos como} um elemento identitário negativo para os outros, não desempenhando, por isso, um papel positivo no processo de construção identitário. Esta conclusão resulta da análise da legislação onde se constata que o beneficiário ideal enquanto categoria oficial se caracteriza como alguém que se encontra numa situação de dependência em relação ao apoio e incapaz de se autonomizar por si próprio (necessitando para o efeito de um programa de inserção). Deste modo, "o acordo de inserção pressupõe não apenas a desinserção (isto é a exclusão social e a pobreza), como também a incapacidade dos indivíduos promoverem a sua própria inserção pelos seus meios. Esta é uma visão negativa dos indivíduos que recorrem ao RMG e são classificados como beneficiários, sendo uma visão com a qual se têm de confrontar "(Diogo, 2007:148). Porém, à luz do material empírico recolhido conclui-se que os beneficiários não se percepcionam como incapazes de gerir os seus destinos, antes pelo contrário, encaram a prestação como um complemento aos seus rendimentos. A percepção do modo como os outros vêm os beneficiários da medida (geralmente negativa) é, para o autor, um significativo marco identitário, já que através daquela os indivíduos reconhecem que o estatuto de beneficiário traz consigo um estigma associado. Também a assunção das críticas que os outros em geral fazem dos beneficiários é igualmente um elemento importante no processo de construção identitária.

\section{- Os beneficiários constroem a sua} identidade perante o RMG e a relação deste com o trabalho através de estratégias de defesa. Tratam-se de estratégias desenvolvidas para reduzir a tensão identitária vivida e que são usadas para minimizar os efeitos adversos da interiorização de uma identidade para os outros negativa. As estratégias de defesa comportam duas dimensões, a racionalização desculpabilizante e a distinção perante os outros. A primeira, mais não é do que a apresentação de um conjunto de argumentos que visa a apresentação de si como beneficiários legítimos da medida. Regra geral, esses argumentos centram-se na descrição da sua situação como sendo de necessidade (ideia associada à escassez de rendimentos provenientes do trabalho ou seja situações de carência material), pela apresentação de si como trabalhador e como alguém que coloca o bem-estar da sua família (e em particular das crianças) acima de tudo, sendo o apoio social um complemento da sua actividade laboral.

A distinção perante os outros diz respeito a distinção efectuada face àqueles que recebem ilegitimamente o RMG (os que aos olhos dos beneficiários gastam de forma reprovável a prestação e os que não trabalham). Aliás, a ideia central do modelo refere-se à legitimidade do recebimento da prestação. Nos argumentos que constroem a legitimidade do recebimento do RMG está o facto de se ser trabalhador destacando-se na análise do material empírico a inextricável relação entre o 
RMG e o trabalho9. "A resistência dos indivíduos em relação às imposições identitárias funda-se, em boa parte, num universo social estruturado em torno do lugar que o trabalho ocupa em relação à família entre os espaços de investimento identitários dos indivíduos. Trabalhar é um dever, sobretudo masculino, para sustentar a família e é em torno desta que encontramos a força da definição de si: trabalham para a família, recebem o RMG para a família" (Diogo, 2007:198).

\section{Em jeito de conclusão}

Apesar do ónus de uma categoria de si negativa, ser beneficiário do RMG é muito importante para a sobrevivência quotidiana a julgar pelo modo como concebem e avaliam o RMG:

- é uma quantia em dinheiro que ajuda à sobrevivência quotidiana (e às despesas que a marcam) da família em geral e das crianças em particular;

- é um complemento ao "magro" e incerto rendimento proveniente do trabalho (Trabalho e RMG surgem nos discursos como formas de angariação de dinheiro para o sustento da família) e, por fim,

- uma ajuda à independência dos indivíduos, na medida em que a ajuda é gerida pelo próprio. Neste sentido os beneficiários definem-se como autónomos e não como dependentes de ajuda para sair da situação de pobreza/exclusão como expressa a legislação da Medida.

É a relação com o trabalho que contribui para atenuar a tensão identitária entre os pobres, em particular entre os beneficiários do RMG/RSI. Contudo, a dificuldade destes em construir uma identidade social em que o trabalho seja um elemento central deve-se às condições em que, de forma geral, o exercem. Assiste-se, de acordo com o autor, a uma "diminuição da importância da relação com trabalho na definição da identidade para si concomitantemente com a manutenção da importância deste relacionamento na definição da identidade para os outros" (Diogo, 2007:58) ${ }^{10}$.

O RSI, tal como o RMG, são medidas que reduzem a incidência da pobreza, tornando-a menos grave e severa, proporcionando condições para tornar o processo de integração social mais fácil. O processo de inserção social é um processo complexo que resulta do próprio processo de construção da inserção na prática.

Tendo em conta os efeitos negativos do RMG no processo de construção identitária resultantes das formas de categorização dos indivíduos geradoras de tensão identitária, e as estratégias de minimização desses efeitos, o autor chega mesmo a equacionar se não se estará como, consideram Gaulejac e Léonetti (1994) perante uma "luta pela dignificação de si perante os outros" (Diogo, 2007:197) ou num "processo de construção identitária revelador da capacidade de resistência dos indivíduos em relação as imposições identitárias" (...), num processo cuja margem de manobra revela o modo como os indivíduos resistem à definição de si imposta pelos outros desenvolvendo estratégias identitárias que os afastam destas formas de identificação" (Diogo, 2007:196). Dito de outro modo, "pode-se descrever o relacionamento dos entrevistados com a medida através da luta pela limitação dos danos identitários provenientes da condição de beneficiário do $R M G^{\prime \prime}$ (Diogo, 2007:197).

\footnotetext{
${ }_{9}$ As situações de doença (e em especial a crónica) surgem também como argumento na legitimação do recebimento do RMG, tal como destaca o autor " a evocação de doenças crónicas no discurso pode ser vista como uma tentativa de reduzir a tensão identitária provocada pela distância entre a definição de si por si e a definição de si pelos outros a partir do estatuto (desvalorizado e desvalorizante) de beneficiário do RMG “ (Diogo, 2007:162).

${ }_{10}$ Fernando Diogo destaca de entre a literatura da especialidade, autores como Sainsaulieu (1998), Paugam (1995) e Dubet e Martuccelli (1998) que defendem o relativo esbatimento do trabalho como princípio identitário, mas também aqueles para quem o trabalho continua sendo central, tal como Schnapper (1989). Em relação aos primeiros, e para citar apenas alguns desses argumentos Dubet e Martuccelli referem que "os indivíduos cessam de se definirem massiva e exclusivamente pela sua relação com o trabalho e voltam-se para um campo plural onde reivindicam, novas competências ou outras pertenças identitárias. Desta forma, para muitos trabalhadores o trabalho não é já uma ética que dê sentido à vida, sendo antes um constrangimento que proporciona recursos para o desenvolvimento de outras actividades". (Dubet e Martuccelli, 1998:11 cit in Diogo, 2007:58). Para além disso, "a dissociação entre as relações de produção e as relações de reprodução devido às transferências de rendimento do Estado-providência com efeitos ao nível da própria estruturação da sociedade" (Diogo, 2007:60). Para Schnapper (1989) ao invés, as sociedades modernas definem-se a partir da produção e o lugar dos indivíduos a partir da sua participação nela. Dubar $(1997,2000)$ relativiza igualmente o esbatimento da centralidade do trabalho na produção identitária quando afirma que a entrada no mercado de trabalho e a relação do indivíduo com a profissão e com o trabalho constituem os elementos mais importante na definição da identidade dos adultos. Por fim, para Baudelot e Establet (2000) o modelo ao qual os indivíduos se referenciam ainda é o pleno emprego (Diogo, 2007:60).
} 


\section{Bibliografia}

CASTRO, Alexandra; CAVALHEIRO, Cecília; QUEDAS, Maria João, RODRIGUES, Fernanda; GUERRA, Florbela e GUERRA, Isabel, 2002, Os beneficiários do RMG: trajectórias de vida, vivências e impactes diferenciados (avaliação de impactes do $R M G$ ), Lisboa, Instituto para o Desenvolvimento Social.

DIOGO, Fernando, 2004a, Quando o Estado e os cidadãos não se entendem: $O$ caso do programa de inserção do rendimento mínimo garantido, Actas dos ateliers do V Congresso Português de Sociologia, Sociedades Contemporâneas: Reflexividade e Acção, Atelier: Exclusões, disponível em www.uac.pt/ fdiogo/ pdffpublicacoes.pdf.

DIOGO, Fernando, 2004b, A parceria: para os beneficiários e em função do desenvolvimento local, Encontro de parceiros dos NLI de S. Miguel e Santa Maria, 22 e 23 de Novembro 2004.
Disponível em http://www.uac.pt/ fdiogo/pdf/Comunica_sobre_parceria.pdf.

DIOGO, Fernando, 2007, Pobreza, Trabalho, Identidade, Lisboa, Celta Editora.

GUERRA, Isabel (coord), LOPES, Elisabete, AMOR, Teresa, 2002, Avaliação de impactes do Rendimento Mínimo Garantido, caracterização dos perfis dos beneficiários RMG, Minorias étnicas, Lisboa, Instituto para o Desenvolvimento Social.

HESPANHA, Pedro, 2002, Algumas questões de fundo para uma avaliação da nova geração de políticas sociais, VII Congreso Internacional del CLAD sobre la Reforma del Estado y de la Administración Pública, Lisboa, Portugal, 8-11 Oct. 2002. 